\title{
OEE Monitoring for Production Processes Based on SCADA/HMI Platform
}

\author{
Lenka Landryová ${ }^{1}$ and Iveta Zolotová ${ }^{2}$ \\ 1 Department of Control Systems and Instrumentation, Faculty of \\ Mechanical Engineering, VŠB - Technical University Ostrava, 17.listopadu \\ 15, 70833 Ostrava-Poruba, Czech Republic, tel. ++420 597234 113, E- \\ mail: Lenka.Landryova@vsb.cz \\ 2 Department of Cybernetics and Artificial Intelligence, Faculty of \\ Electrotechnics and Informatics, Technical University Kosice, Letná 9, 042 \\ 00 Kosice, Slovak Republic, tel, +421 556022 570, E-mail: \\ Iveta.Zolotova@tuke.sk
}

\begin{abstract}
This article aims to show the problem of Overall Equipment Effectiveness (OEE) monitoring and performance measurement on a case study done in a small company. Losses occur during the production process and the ways of detecting them must be analyzed. The methodology for calculating total Overall Equipment Effectiveness is followed while applying monitoring tools. Some existing methods used for production control, the flow of material and production facilities control and monitoring, and the methods used for maintenance control are demonstrated as examples regarding data acquisition, collecting idle time or occurred accidents. The tools and methods implemented for maintenance control can vary depending on, among other areas, the operational conditions, but when visualization application can be designed for monitored technological process on the SCADA/HMI platform, the implementation can be described as shown in this article.
\end{abstract}

Keywords
Monitoring, performance, equipment effectiveness.

\section{Introduction}

Although each production is specific, all of them deal with downtimes, losses, which unable us to reach the maximum theoretical production performance. What can be considered as a loss can be further explained and divided into these four basic categories based on the reasons for their occurrence: 
1. Planned downtime includes days of work off, state holidays, time for overhaul, time for cleaning the workplace, but even development and testing, in some cases, can be considered as a loss;

2. Operational loss includes time for setting up machines, time for changes in production, waiting time for material delivery, and time wasted with bottlenecks or by operator's mistakes, as well as breakdowns;

3. Performance loss occurs due to wrong machine settings, slowing down the production cycle or causing failures;

4. Quality problems with material defects and product rejects, production imperfections, reworks, and repairs decrease efficiency and production effectiveness.

As demonstrated on the above mentioned categories, some causes produce losses qualified in more than just one way. They can touch availability, performance and /or quality issues at the same time since downtime losses, for example, can cause losses in speed and quality at the same time.

\section{Methodology for OEE Calculation}

Wauters and Mathot [4] describe two types of OEE, the total OEE, which has to do with the theoretical production time, and the OEE dealing with available production time. In other words, the total OEE is the sum of available production time (OEE value) and external losses.

Available production time consists of valuable operating time and technical losses. The OEE coefficient calculated is then a quotient of the valuable operating time against the available production time and speaks about technical losses only, when it decreases and equals less than $100 \%$.

External losses are planned and unplanned:

- Planned losses consist of revisions done, lack of demand for the products, authorized breaks or free weekends for employees;

- Unplanned losses include insufficient material delivery, lack of personnel (sick leaves and epidemics), additional administration or ecological agreements.

The valuable operating time against the theoretical production time results in the total OEE as an indication of how effectively machines have been used compared to how their use could theoretically be maximized. This tells us now about not only the technical issues, but also organizational and social consequences within the production.

\section{Monitoring of OEE}

When talking about production optimization, standards should be implemented, so that it would be possible to measure and express problems in numbers and based on knowledge. Correct, complete and up-to-date data about production events are necessary. 


\section{1 A manual method}

Monitored values are written by foremen, workers setting the machines and equipment, etc. into working sheets. Calculations of OEE are performed most commonly in MS Excel. The first occasion to make mistakes occur when transferring data from the workbooks into the PC. Furthermore, daily/weekly values are rounded up and in terms of months and years the final report may show much differentiated data from the reality.

Manual records about downtimes put an extra load on operators from production lines. Therefore, companies introduce easier ways for reporting, such as establishing average times for a concrete type of breakdown, neglecting shorter stoppages, etc. These result in incorrect calculations of overall equipment effectiveness.

For example, a company produces its products on two production lines, but for the optimization reasons, only a line producing more results will be analyzed. A certain time period is analyzed; during April till December of 2007 the theoretical production time is 274 days. This corresponds to $274 \times 24=6576$ hours. The available production time is calculated as 274 days minus days, when work was not planned for weekends (79), state holidays (8) and annual leave (15) of employees, resulting in 172 days. For two shifts of 8 hours per day in total there are $172 \times 2 \times 8$ $=2752$ hours of work during shifts. If work stoppages and pauses last about 1 hour every day for both production lines, then it is $2752-172=2580$ hours. The lack of personnel or raw materials causing the rest of the time losses cannot be directly obtained; an estimate has to be made. The head of production decides upon $5 \%$, so the available production time $2752 \times 0.95=2614.4$ hours. Then the valuable operating time was calculated from the throughput of production lines and the amount produced resulting in 1205 hours.

Table 1. Manually calculated coefficients

\begin{tabular}{|l|l|l|l|}
\hline & & OEE & Total OEE \\
\hline Valuable operating time & 1205 hours & $1205 / 2614=0.46$ & \\
\cline { 1 - 2 } Available production time & 2614 hours & $46 \%$ & $1205 / 6576=0.18$ \\
\hline Theoretical production time & 6576 hours & & $18 \%$ \\
\hline
\end{tabular}

This simple way of calculation is not sufficient for many companies, which are, for many other various reasons, introducing Enterprise Resources Planning (ERP) type of information systems. With the ERP systems the process is gradually semi- or completely automated.

\section{2 Semi- automated method}

At the present time, the small company (where the case study was run) still keeps operation books as the primary sources of data. Reports into the BRAIN ERP system introduced not long ago are sent by certain workers usually at the end of each shift. The reports consist of:

- Amount of good products produced 
- Produced amount of rejects

- Time needed for production of good products

- Time spent on producing rejects

- Codes indicating the way how a reject was made

- Stoppages, idle time and extra work with their codes (see Fig. 1).

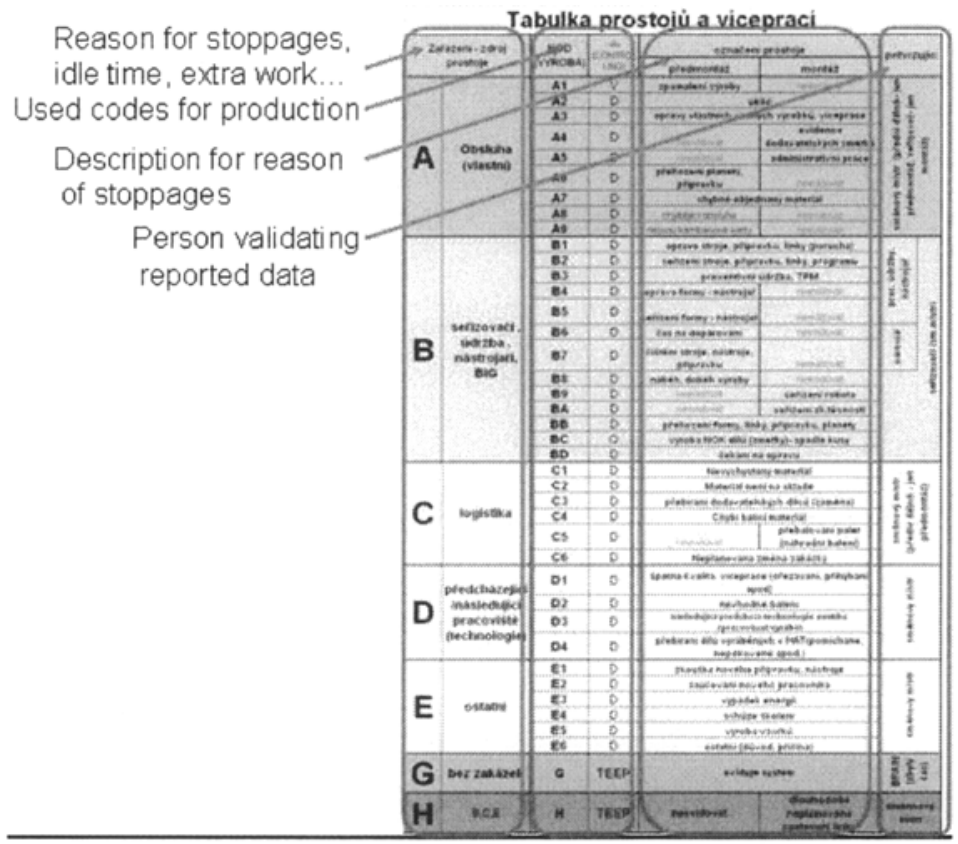

Fig. 1. Table of reported data

The database then provides the fundamental source of production data needed for indicator calculations, such as:

- Fulfillment performance standards

- Calculation of product prize

- Capacity burden

- Production efficiency, overall equipment efficiency

- Production rejects

- Production planning

- KPI (Key Performance Indicator) reports and statements.

Data is read into the Merit controlling system, which processes it resulting in graphical outputs (see Fig. 2) and stoppages and extra work breakups. This data is also provided further as an information source for other departments and units within a company. 


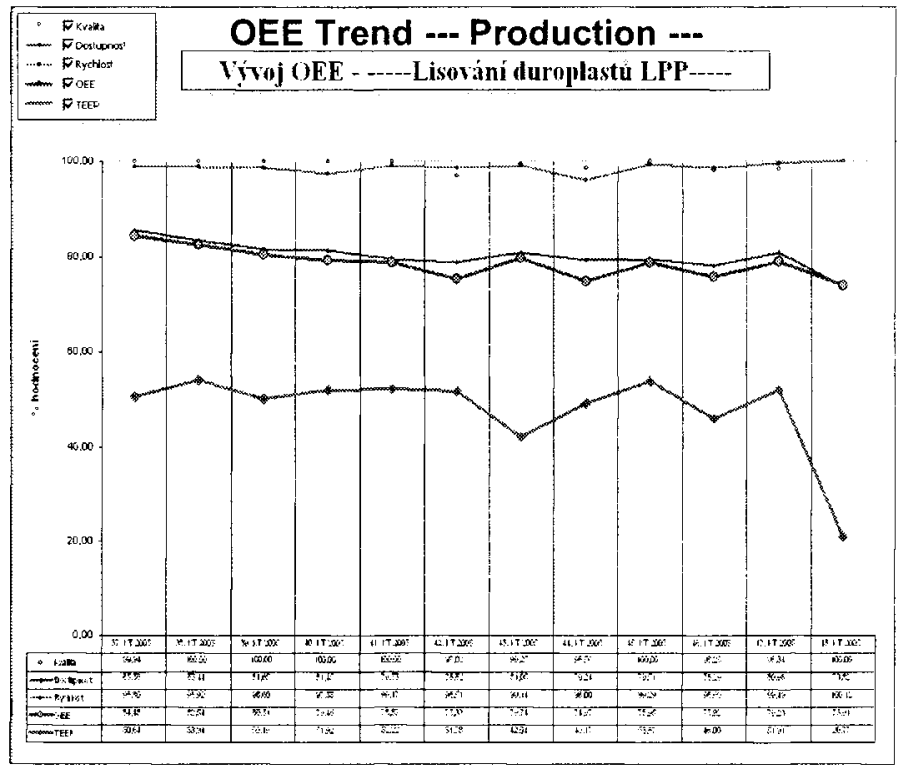

Fig. 2. Tools modeling, executing, and tracking information associated with material and control flow across the plant.

By defining views and requests, the system processes data and filters it according to the time period requested, where the weekly report is the minimum time period, regarding each workplace or a group of them, technology, and a company.

\section{3 Integrating control systems with equipment and maintenance monitoring}

Real time monitoring enables recording causes of stoppages of a different kind, which can occur even within a small time period in different production technologies and areas of a shop floor; the real causes can be identified then. These monitoring systems help find:

- a hidden production capacity for even better utilization of production equipment

- reason for investments into new machines,

- more accurate maintenance intervals and OEE measurement setting.

Using standard IT technologies makes integration of a control system easier with the company's higher level information system (MES, ERP aj.) 


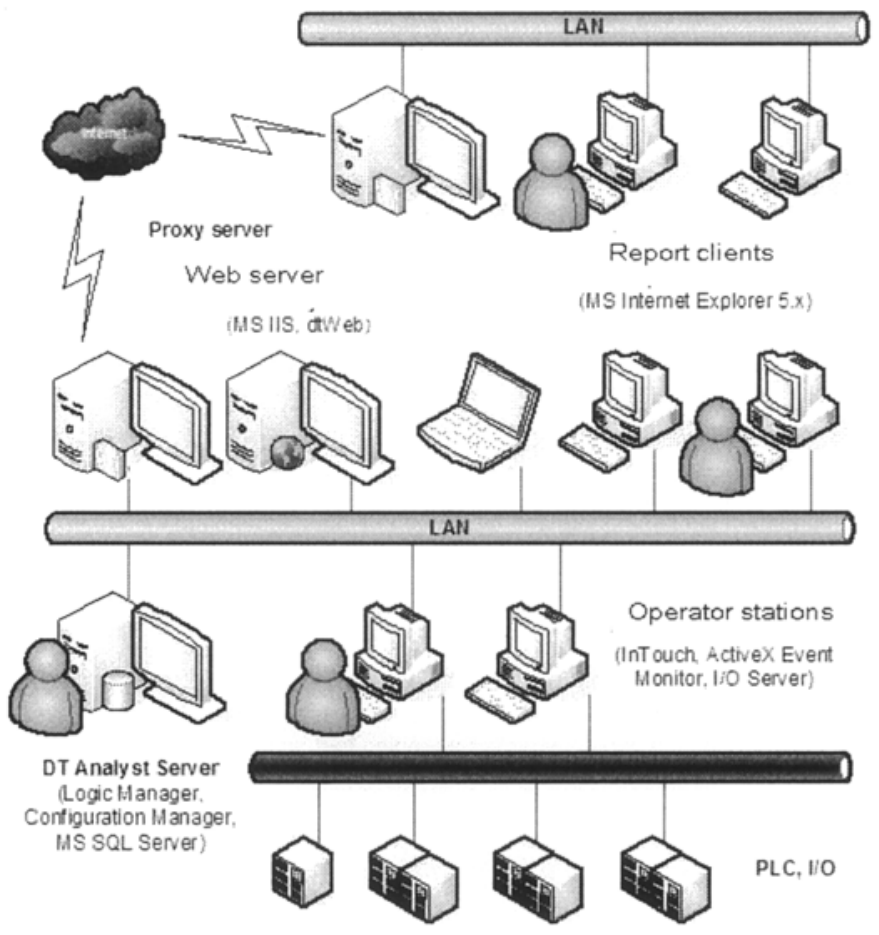

Fig. 3. An architecture of a control system configured with downtime analytical and reporting tools. [3]

The simulated application was designed in InTouch visualization environment to demonstrate the process. $[1,2]$ The visualized process is simulated by running several scripts: the application script for animating process, conditional scripts linked to simulated breakdowns, and other scripts. For monitoring downtimes and total OEE calculations in the environment of InTouch supervisory control system, the DT Analyst 2.2 software [5] was configured. The Configuration Manager of DT Analyst enabled the definition of stoppages and their causes and the configuration of the entire system. The graphical user interface (GUI) enabled defining new causes and new causalities and combinations of downtimes to tune the system up. The ActiveX Event Monitor (see Fig. 4) is running on an operator station and allows a system operator to execute and manually enter additional information about downtime events. An operator can run scheduled downtimes, which did not result from PLC indicated alarms, such as production changes, cleaning machines, and other scheduled maintenance. The user application also defines entirely automated execution based on occurred downtimes from the controlled process. 


\begin{tabular}{|c|c|c|c|}
\hline System & Downime Defintion & Started & Duration \\
\hline \$) PACAAGING & MANULAL DT - Clearing & $13: 41: 14$ & $00.00: 12$ \\
\hline if PACKAGING & Funning downtime event Corveyor Falure & 13.4000 & $0001: 14$ \\
\hline श्? BATCHING & BATC Fling Falure & 1329.19 & 00.07 .53 \\
\hline ब्र BATCHING & BATC FIIng Falue & $13: 2836$ & 0000.17 \\
\hline शी BATCHING & Asxic ufoing folute & 132756 & 0000.11 \\
\hline शf PACKAGING & Finished runtime events poles Emply & $13: 2222$ & $00.01: 12$ \\
\hline If PACKAGING & Sivesor Folue & 13.17 .26 & $00.04: 47$ \\
\hline 9) PACRAGING & PAOK Corweyor Speed & $13: 1632$ & 000020 \\
\hline ef PACKAGING & PACK Labeler Empty & 13.16 .15 & 00.00 .05 \\
\hline 9 PACKAGING & PACK Conveyor Falure & $13: 15,58$ & 000010 \\
\hline
\end{tabular}

Fig. 4. Event Monitor user interface

The integration of the visualized process and downtime analytical environment resulted in a comfortable environment for a process operator, who needs to read OEE and other KPI indicators (see Fig. 5).

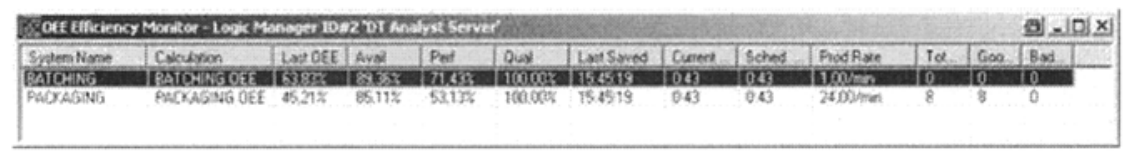

Fig. 5. OEE Efficiency monitor window of Logic Manager application

\section{Conclusions}

Some possibilities of online events monitoring and the interaction with a supervisor are demonstrated in the examples. A demo-application, which was designed during the course of research can serve as a training example and is aimed at university students as well as trainees from companies. The reasons for analyzing this problem in the conditions of a small company shall inspire readers from such a working environment and complement general trends set up by leaders in the area of industrial automation.

The technical aspects of the implementation as a simulation model in the university computer lab are analyzed giving an overview of constraints regarding software and hardware issues.

The method used for automatic data acquisition and evaluation seems to be suitable for the objective recording of all downtimes given the precise length and type. Monitoring in a real time enables recording causes for various types of downtimes, which can occur with a very small time difference and in different parts of production technology and/or areas of a plant floor, therefore it shows the exact downtime causes. An advantage of this method is that operators do not need to record the data manually into their operating books and then copy the data later in order to use analytical tools calculating the total equipment effectiveness of production equipment, which can be in many cases part of a separate system. This 
approach eliminates human errors and other types of deviations. In this way the system configured for monitoring, data acquisition, visualization and data analysis can then warn the operators about the downtime in a friendly environment with the help of a human-machine interface. The method of automatic data acquisition can be used in production, which is not, for various reasons, fully automated yet.

This paper was written based on experience from the operation of a small company and cooperation with a part-time university student working there, preceding the analysis of a SCADA/HMI system available at the university department and its features enabling the OEE monitoring. For the monitoring and visualization of a simulated technological process SCADA/HMI software was used and configured with cooperating modules creating a supervisory control PC station similar to those, which are already used in practice in large production companies for the purpose of monitoring the total OEE. The work concluded in this case study demonstrates the possibilities for smaller operations and helps the decision-makers in choosing system solutions for innovative processes.

\section{Acknowledgements}

The work presented in the paper is supported by the Slovak Grant Academy KEGA grant project 3/4230/06 and by the Czech Ministry of Education grant project 1P05LA266. Furthermore, the authors thank to Pantek (CS) distributor who provided us with free licenses and donkeys used with the professional software environment for educational purposes.

\section{References}

1. Babiuch, M. The Usage of the New Technologies at the Education at the Department of Control Systems and Instrumentation. Transactions of the VSBTechnical University Ostrava, Mechanical Series, year LII, 2006, Part No. II, Contribution No. 1525, pp. 7-12. ISSN 1210-0471. ISBN 80-248-1211-8.

2. Landryová, L., Zolotová, I., Bakoš, M. Teaching Supervisory Control Based on a Web Portal and a System of Laboratory Tasks. In: Education for the $21 \mathrm{st}$ Century - Impact of ICT and Digital Resources. Springer Boston, USA, 2006, pp. 351-355. ISSN 1571-5736 (Print) 1861-2288 (Online)

3. Pantek (CS) s.r.o.: Documentation for DT Analyst software [online]. Hradec Králové: Pantek (CS) s.r.o., 2005 [cit. 2005-12-20]. PDF format. Available from: <URL: http://www.pantek.cz/index.asp>

4. Wauters, F. - Mathot, J.: OEE White paper [online]. Zurych (Switzerland): ABB Ltd., June 2002 [cit. 2005-12-16]. PDF format. Available from: <URL: http://library.abb.com//Overall Equipment Effectiveness.pdf $>$

5. Wonderware: DT Analyst Application Guide [CD ROM]. Lake Forest (California - USA): Invensys Systems Inc., August 2003. PDF format. 